\title{
THE PROBLEMS AND POSSIBLE SOLUTIONS IN DEVELOPMENT OF CHINESE DEAF IDENTITY
}

\author{
Ge Chen*
}

\begin{abstract}
"Deaf Identity" is a new concept in China; in this article the author analyzes the development of Deaf Identity based on Glickman's research, lists the problems, namely the attitude of parents, the inadequate deaf education and some misunderstandings ofthe deaf culture, in the development of Chinese Deaf Identity from a cultural perspective. And then he tries to solve the problems from several approaches, which improve the parents' ability, expand the deaf culture in deaf school and ameliorate the public's attitude to the deaf culture.
\end{abstract}

\section{Keywords}

Deaf Identity; Deaf Identity Development; China; Family Environment; Deaf Education; Social Culture

Deaf Identity was researched in the field of pedagogy, psychology and sociology in the West decades ago, but "Deaf Identity" is a new concept in China.

China has more than 20 million deaf people, i.e. $1.67 \%$ of Chinese population and more than 800 thousands are children below 7 years old. Deaf people in general do not have high education, and there is a little communication with each other, a few individuals even do not know that there are another deaf in the world. So they cannot identify themselves with the culture. The deaf will feel lonely and anxious because of their excursive and uncertain identity.

In this article, I will discuss the problems in the development of Chinese deaf identity and its solutions using the research of "Deaf Identity" in western society.

* Ge Chen, Doctoral student, Institute of Special Education, Faculty of Education, Palacky University, Olomouc, Czech Republic; Lecture, Faculty of Education, Sichuan Normal University, China. 


\section{The Development of Deaf Identity}

Deaf Identity came into being with the development of the deaf cultural movement, the arousal of the deaf rights and dignity, and the development of the deaf education.

Glickman elaborated the development of Deaf Cultural Identity, his research reminded us that we should recognize firstly: Deaf people and hearing people only have the "cultural difference", and we must understand deaf culture and the other culture of the minority as equal. ${ }^{1}$ The development of Deaf Identity is a kind of the manifestations of theory of cultural and ethnical identity. I will explain the "Deaf Identity" base on the Glickman's comprehension.

\subsection{Deaf Cultural Identity}

In the different types of the disabled people, only deaf emphasize deaf culture, the other disabled do not have an obvious and distinct culture. ${ }^{2}$ The concept of Deaf culture has proved of the utmost importance in wresting social power from an overwhelming hearing majority who have not only systemically privileged spoken language over visual language but who have also forced this spoken language on deaf people, both unsuccessfully and at the expense of a natural language equally capable of expressing abstract thought. ${ }^{3}$ There are three reasons about the appearance of the deaf culture and deaf society, the first reason is that communication is the only barrier between the deaf persons and the mainstream culture, and this barrier is a distinct characteristic that refers to deaf as different from the other crowd. The second one is that the deaf have the unique communicate means-sign language, and the last reason is that strong attraction in the deaf crowd (deaf school is the foremost deaf crowd). So if we do not treat the deaf as disabled, but in the view of culture, deaf people are a kind of minority that has some difference in the ways of communication and the content of the life, or we can say they only have the difference in culture in comparison with the mainstream.

1 GLICKMAN,NEIL S., CAREY, JOHN C. Measuring Deaf Cultural Identities: A Preliminary Investigation, Rehabilitation Psychology, Vol. 39(3), Fal, 1994.

2 HU YANMEI, Study on Deaf College Identity, Liaoning Normal University Ph.D. thesis, p. 41, 2005.

3 BENJAMIN R FRASER, Deaf Cultural Production in Twentieth-Century Madrid, Sign Language Studies, Vol. 7(4), Summer 2007. 
So deaf people live in two types of culture which is the hearing culture and deaf culture. The deaf people identify with themselves, not just identify with the "disabled" but identify with the deaf culture, namely they enter into the deaf society and deaf crowd, and identify with the hearing culture which they live in.

\subsection{The Diversity of Deaf Identity}

A scale that measures deaf identities includes these three, labeling them "hearing identity" (perceiving deafness as a disability), "immersion" (perceiving deafness as a culture), and "bicultural". Fourth, "marginal" identity is proposed, of people who are not sure about their feelings toward their deafness. ${ }^{4}$ I explain them in detail; Hearing identity applies to the deaf people who prefer to interact with the hearing people as much as possible and keep contacts with the other deaf people to a minimum. The hearing identity deaf people would disdain sign language as a crutch, take pride in the ability to function in the hearing world. In contrast, the immersion deaf people who reject all involvement with the hearing people, such a person would feel oppressed by hearing people and probably would make no effort to communicate with them. The bicultural identity applies to the deaf person who feels comfortable in both hearing and deaf culture. This person probably would make excellent use of whatever residual hearing he or she possessed, and would sign competently. They would enjoy hearing friends as much as deaf peers. The last one, marginal identity applies to the deaf person who is truly comfortable neither in hearing culture nor among in the deaf community.

Thomas K. Holcomb devised seven identity categories, a deaf person may fall into based on extent of exposure to the deaf community: balanced bicultural, deaf-dominant bicultural, hearing-dominant bicultural, culturally isolated, culturally separate, culturally marginal, and culturally captive. ${ }^{5}$ In these different categories, balanced bicultural, deaf-dominant bicultural and hearing-dominant bicultural that are minutia of the bicultural identity. And the culturally separate identity, the culturally isolated identity and the culturally marginal identity correspond to the immersion identity, the hearing

4 YAEL BAT-CHAVA, Diversity of Deaf Identities, American Annals of the Deaf, Vol. 145(5), Dec 2000

5 THOMAS K. HOLCOMB, Development of Deaf Bicultural Identity, American Annals of the Deaf, Vol. 142(2), Apr 1997 
identity and the marginal identity probably. Beside, Thomas K. Holcomb proposed another category: the culturally captive. That applies to the deaf person who has had no opportunity to meet other deaf people and learn about Deaf culture.

\subsection{The Development of Deaf Identity}

Glickman and Thomas K. Holcomb devised a different Deaf Identity classification. But there is an ongoing flux in terms of how deaf people define themselves as individuals and members of their cultures. ${ }^{6}$ Glickman and Thomas K. Holcomb have asimilar idea about the stage of the Deaf Identity development as follow: Hearing Identity, Marginal identity, Immersion and Bicultural Identity.

Bicultural Identity is the last stage, but acquiring a bicultural identity, whether it is balanced bicultural, deaf-dominant bicultural, or hearing dominant bicultural, is crucial for most deaf people in developing a productive, rewarding life. Unfortunately, the process of developing such a bicultural identity can be long and painful for some. In this process, the deaf people's emotion will have five stages: 1) conformity, 2) dissonance, 3) resistance and immersion, 4) introspection and 5) awareness. ${ }^{\text {? }}$

Most deaf people are born to hearing parents, who communicate and educate their children in speaking language all the time. There are too much negation about the deaf, the sign language and the style of deaf in the individual's growth environment. Then the deaf person will conform to the around environment, and identify the hearing culture. But with improving the self-awareness of deaf person, especially after the individual meets the other deaf person, they will feel that they cannot enter both the hearing and deaf communication and their identity will be dissonant. With the more contact with the deaf crowd, the more affirmative themselves; they immerse themselves in the deaf culture. The deaf will introspect themselves after change the identity, and then they will understand and be aware of the difference between the deaf culture and the hearing culture.

${ }^{6}$ Deborah L. Maxwell-McCaw, Irene W. Leigh, Alan L. Marcus Gallaudet University, Social Identity in Deaf Culture: A Comparison of Ideologies, used with permission, draft mailed to Journal of the American Deafness \& Rehabilitation Association, p. 9.

7 THOMAS K. HOLCOMB, Development of Deaf Bicultural Identity, American Annals of the Deaf, Vol. 142(2), Apr 1997 
Besides, there are some differences in the Deaf Identity Development.

Firstly, hearing identity is not the beginning of the Deaf Identity development forever. According to the experience of every deaf person, the first stage of the Deaf Identity is different. For example, the deaf who are born in a deaf family, the individuals who become deaf when they are adult and so on.

Secondly, although in the same development stage, there are some divergences of individuals.

\section{The Problems and Reasons in Chinese Deaf Identity Development}

Study in Deaf Identity is a new project in China. There are only two Chinese publications examining "Deaf Identity" in the range that I can find it so far. One is a Ph.D. thesis by a young scholar (Hu Yamei's <Study on Deaf Identity of the deaf college students $\rangle$ ), another one is $\langle$ Study on Deaf Identity> published in <Chinese Special Education>. So, it is difficult to show a complete and accurate statistics that about the number of deaf people in different stages of the Deaf Identity Development. But I found some problems in the current development of Deaf Identity in China from related published sources. In the following paragraphs, I describe them and try to analyze the reasons.

\subsection{Many Deaf People Identify Hearing Culture Due to Family Environment}

Most deaf children ( $90 \%$ ) are born to hearing parents, who previously never thought much about deafness. Bat-Chava's hypothesis is that children whose parents are hearing or who grew up in homes where spoken language was the primary mode of communication will be likely to adopt the view of deafness as a disability, and develop a culturally hearing identity. ${ }^{8}$ And this hypothesis was tested to be true at last.

There are two challenges making deaf children get conditioned by the hearing culture in Chinese hearing families as following:

\subsubsection{The Mode of Communication in the Family}

The first related feature of the family environment is the communication method used in the home. The mode of communication influences the

8 YAEL BAT-CHAVA, Diversity of Deaf Identities, American Annals of the Deaf, Vol. 145(5), Dec 2000 
description of personal identity. ${ }^{9}$ In general, hearing parents cannot use sign language in China, just like the families in other countries. In the past, most hearing parents were advised not to use signs or gestures with their deaf child, but rather to talk to him or her. Heeding professionals' advice, these parents tried to educate their children by means of the oral method ${ }^{10}$. But these practices, which are less prevalent in western society today, affected the participants in the present study. Until now, almost every hearing parent still communicates with their deaf children in oral language in China and they avoid using signs in their family. The deaf children know nothing about the deaf culture as a deaf, and then they think only the hearing culture is a normal culture, gradually identify with the hearing culture.

\subsubsection{Parents' Attitude to Deaf Children}

The second related feature of the family environment is the parents' attitude. Health professionals and educators, who hold the view that deafness is a disability, shape parents' initial views of deafness. Most hearing parents cannot accept the actuality that their children are disabled, they do not acknowledge their children's deafness, do not wish the children to enter the deaf community, they hope that their children will become "normal persons". So the hearing parents usually feel disappointment, anxiety, helpless and compunction.

In the families, the disadvantage of viewing deaf children from the disabled perspective is that it will be transmitted to the deaf children. Such parents' deaf children will likely adhere to this feeling and view as well. ${ }^{11}$ And the deaf children will identify culturally hearing.

In contrast, deaf children whose parents or siblings (or both) are members of the Deaf community are more likely to be exposed to the cultural model of deafness through interaction with their family and the Deaf community.

9 JOANNA KOSSEWSKA, Personal Identity in Deaf Adolescents, Journal of Special Education and Rehabilitation, Vol. 1-2, p. 67,2008

10 YAEL BAT-CHAVA, Diversity of Deaf Identities, American Annals of the Deaf, Vol. 145(5), Dec 2000

11 YAEL BAT-CHAVA, Diversity of Deaf Identities, American Annals of the Deaf, Vol. 145(5), p. 421, Dec 2000 


\subsection{Many Deaf Persons Identify "Marginal" Due to Education Environment}

There are two kinds of educational settings for deaf children in China, one is deaf school, and the other is general school. Neither deaf schools nor general schools provide enough deaf culture for deaf students. Hu Yamei noted: The deaf children who study at general school are less identified with the hearing culture than the deaf children who study at deaf school, no matter how long they stay at general school. Moreover, the deaf children who study only at deaf school are more identified with the culturally deaf than the deaf children who study only at general school. ${ }^{12}$

In China, there are two kinds of current situations making the deaf neither identify with the hearing culture nor understand the deaf culture, and then their identity will be "marginal". Firstly, Magda Nikolaraizi \& Kika Hadjikakou pointed out that the most critical educational experiences for the participants' identity concerned their interactions with hearing or deaf peers and their language of communication with their peers at school. ${ }^{13} \mathrm{But}$ in China, a lot of deaf children who live in villages have no opportunity to study at deaf school, they choose only general school or even do not go to school. Secondly, even if the deaf children who are lucky to study at deaf schools, they find there is not enough the deaf culture as expected by the deaf crowd yet.

\subsubsection{Teaching Language is "Oral Main, Sign Auxiliary"}

Bilingual education (ASL and English) has been popular at deaf schools in the West since the 1980s. The hearing culture and deaf culture coexist by using simultaneously two languages, it is a great benefit for deaf persons who can understand and adapt to the two kinds of different cultures, and then identify with the bicultural identity.

But in China, the teaching language's history will be traced back to the well documented 1880 conference in Milan, Italy, at which oral education methods for teaching deaf children were given recognition as superior to those of manual education incorporating sign language. Two missionaries

12 HU YANMEI, Study on Deaf College Identity, Liaoning Normal University Ph.D. thesis, p. 41, 2005.

13 MAGDA NIKOLARAIZI \& KIKA HADJIKAKOU, The Role of Educational Experiences in the Development of Deaf Identity, Journal of Deaf Studies and Deaf Education Vol. 11(4), p. 477, Fall 2006. 
working in China attended the Milan Conference. After Milan, the Rev. Charles Rogers Mills and his wife, Annette Thompson Mills, returned to China, where in 1887 they established the first documented school for the deaf, the Chefoo School for the Deaf in Tungchow. Since that time, the oral approach has continued to be the dominant approach promoted by Chinese governments and by educators in China. ${ }^{14}$ In 1954, a national conference on the teaching of the Chinese language at schools for the deaf concluded that oral teaching was still the best practice. ${ }^{15}$

The western method of "bilingual education" has much influence to the Chinese deaf education. But the approach of "Oral is main, sign and printed is auxiliary" is still the foremost teaching method at Chinese deaf school for a long time. In the class, the more use of the oral language, the more despise of the sign language. When the deaf students graduate and enter society, they will find that they cannot overcome communication barriers with the hearing world. But then they are not good at their mother language-Chinese Sign Language, they cannot communicate easily with other deaf persons. Many deaf persons acquire the "marginal" identity.

\subsubsection{Teachers' problems}

The teachers who work at deaf schools have some problems as following: Firstly, the sign language is the core of the deaf culture, but most of the teachers who work at deaf school (especially hearing teachers) are not good at CSL. When the teacher utilizes CSL, only $20.8 \%$ deaf students can understand completely, $51.7 \%$ deaf students can understand majority, and $26.7 \%$ deaf students just know a little of them. ${ }^{16}$ With promoting "bilingual education" in the West, more and more deaf school's teachers realize CSL is important and necessary. But until now, most teachers in deaf school cannot communicate with deaf students fluently. There are several reasons for the teachers' bad sign language. For example, being affected by the oral approach

14 RICHARD R. LYTLE, KATHRYN E. JOHNSON, YANG JUNHUI, Deaf Education in China: History, Current Issues, and Emerging Deaf Voices, American Annals of The Deaf, Vol. 150(5), p. 458, 2005/2006

15 RICHARD R. LYTLE, KATHRYN E. JOHNSON, YANG JUNHUI, Deaf Education in China: History, Current Issues, and Emerging Deaf Voices, American Annals of The Deaf, Vol. 150(5), p. 458, 2005/2006

16 HU YANMEI, Study on Deaf College Identity, Liaoning Normal University Ph.D. thesis, p. $45,2005$. 
that can be traced back to the 1880 s, having mistake the natural sign language from the deaf students ${ }^{17}$, teachers lacking the CSL training and etc.

Secondly, the deaf students have their style and feature, but they are taught by the similar method like normal students. For instance, the first high class endeavouring to enter a higher school was built in Nanjing Deaf School in 1992. A deaf lady who graduated from this school recalled her English teacher, she said: He found the English alphabet pictures, but he learn us how to read them, his method came as a great shock to us all, we are all deaf, we can't hear it. Is reading necessary for us? Although it is a long time from 1992, today many teachers who work at deaf school still use similar teaching methods like to normal students, they do not pay attention to the difference of the deaf culture.

\subsubsection{Problem of Curriculum}

The curriculum of deaf school does not have any obvious feature of the deaf culture, the curriculum for deaf children in China reflects the curriculum prescribed for all elementary and middle school children without disabilities, it emphasizes the acquisition of knowledge through a great deal of skill and drill.

In my article, I show only one case to explain the problem of the curriculum content. A piece of a Chinese text, <The Picture of Snow>, in Grade Six of general school was shifted to Grade Five of deaf school, and the sentences what describe the sound were deleted for deaf children. In my opinion, the adjustment and alteration are not good enough for deaf students.

\subsection{Chinese Deaf Identity Development is Difficult Due to Culture Environment}

The deaf culture is a distinct culture in China. The heterogeneity of the deaf community, ${ }^{18}$ the sign language as its core, is embodied in psychology and action of deaf people. But in China, a lot of public do not comprehend the deaf culture as a kind of a normal and equal subculture, and the public do not really understand and respect the deaf culture. They believe the hear-

17 LIANGH HAO, Research on CSL Study by Hearing Teachers in Deaf School. Published on Internet, Jan, 2010.

18 ILA PARASNIS, Cultural identity and diversity in deaf education, American Annals of the Deaf; Vol. 142(2), p. 73, Apr 1997; 142,2 
ing status should be an innate physical characteristic. The deaf culture is neglected and discriminated partly due to incomprehension and low esteem.

Now, we do not realize the existence of the deaf culture is necessary, in our view, the deaf people are just disabled people, and we always try our best to let them return the mainstream culture.

This realization that the deaf culture affects the deaf person's life by parents, school and the colleagues, and affects the deaf identify itself. The deaf want to extricate themselves from the "abnormal" culture. So, some deaf persons identify with the hearing culture, make friends with the hearing people, avoid using the sign language, and look forward to becoming a hearing man. In contrast, some deaf hate the hearing society, wallow in self-pity. Beside some deaf refuse their culture, but they do also not enter the "normal" and mainstream culture completely.

\section{Solutions}

In the investigation of S. H. Cole \& R. J. Edelmann, the teacher who educates the deaf students believes that the deaf who identify as bicultural have least problems. ${ }^{19}$

Deaf college students' acceptance and integration in the deaf and hearing culture are helpful for fulfilling of self-esteem. ${ }^{20}$

When a deaf person comes to a fair and realistic understanding of both cultures, and can relate comfortably to both ${ }^{21}$ it is the final stage of the development of Deaf Identity.

The more identification with the bicultural identity, the less social anxiety about the deaf students. ${ }^{22}$

From the previous lists we can find that different authors believe the same - that the bicultural identity is the healthiest stage of the development

19 COLE S. H., Edelmann, R. J., Identity Patterns and Self- and Teacher-perceptions of Problems for Deaf Adolescents: a Research Note, Journal of Child Psychology and Psychiatry and Allied Disciplines. Vol. 32(7), Nov 1991.

20 HU YANMEI, Study on Deaf College Identity, Liaoning Normal University Ph.D. thesis, p. 45, 2005.

21 THOMAS K. HOLCOMB, Development of Deaf Bicultural Identity, American Annals of the Deaf, Vol. 142(2), p. 91, Apr 1997

22 TAN QIAOBAO, ZHONG YIPING, CHEN FANG, ZHOU SONGQING, Research on the Relationship Between Identity and Social Anxiety of Deaf Students, Chinese Journal of Clinical Psychology Vol. 18 (4), p. 513, 2010 
of Deaf Identity. So, my solutions are to give some advises to the deaf who develop their bicultural identity.

\subsection{Pay Close Attention to Family and Parents}

The communication and the attitude of parents influence the development of Deaf Identity. In the future, we must shift the parents' focus from disability to diversity by the following different ways:

\subsubsection{Communicate with Linguists}

Chinese parents look at their deaf children as only disabled because most hearing parents know nothing about the deaf society and deaf culture, they don't know how to help and educate their deaf children, and they do not know what attitude or expectation is the best one for their children.

The linguists, especially those who work at university and rehabilitation centres could provide the necessary knowledge and support to the parents who have deaf children, guide the parents to the best way to communicate with their children.

The communicative approach between linguists and parents should be diversity, for example, the researchers visit the family regularly, the parents consult by telephone, communicate on the internet and so on. If we have built this communication platform, both linguists and parents can try their best together, provide the best growth in the family environment.

\subsubsection{A Role of Community Support to Families with Hearing Impaired Member}

There is an inevitable gap between deaf people and hearing persons because of the deafness. Many parents who have deaf children live in fear and trepidation due to this gap, including the deaf children's education, jobs and marriage in the future and so on. And this trepidation is the reason why most parents want to change the disabled situation of their children.

If community pays more attention to the family that have deaf children, they can give assistance to the parents, for example, take care of the deaf kids when the parents leave, help parents choose the school for their deaf students, supply the simple jobs to the deaf persons and so on. The more help to their deaf children, the less anxiety of the parents. 


\subsubsection{Provide Necessary "Deaf Culture" to Deaf Children}

Some deaf people who live in the hearing family know a little about other deaf persons. It will affect the identity development of the deaf children if they learn nothing about the deaf society and deaf culture.

So we must provide the necessary "Deaf Culture" to deaf children, we can do something as following: We can get help from the research institute and invite a successful deaf person to communicate with deaf children, we can get help from the community to organize a deaf salon and etc. Try our best to provide opportunities to deaf children.

\subsection{Expand the Deaf Culture in Deaf School and Deaf Education}

To aim at the problems that are mentioned in the above paragraph, we have some ways as following:

\subsubsection{Reform the Teaching Language in Deaf School}

Reforming the teaching language in deaf school means improvement of the frequency and position of the sign language at deaf school. The sign language (CSL) must be as important as the oral language. The bilingual education not only improves the power of teacher to study CSL but also benefits the deaf students to study their "mother language". Then deaf students can identify culturally with both the deaf and hearing culture.

\subsubsection{Improve the Training and Education to Teachers}

Most of the teachers who work at deaf schools are not graduates from a special college but come from the normal university. So they are not proficient in CSL, and they do not understand the deaf life and deaf culture.

Improving education for teachers means that the university should improve the major of special education and train more and more graduates for deaf schools. These graduates who have special knowledge and professional skills can give better services for deaf schools.

Training for teachers means training for graduates who become teachers at deaf school. The training platform is built by research institutes, universities and teachers at deaf school, the content of the training includes the skill of CSL, special knowledge, teaching methods for deaf students and so on; every deaf school must ensure that the offer of opportunities enables every teacher to take part in the training in policy. 


\subsubsection{Enrich the Curriculum at Deaf School}

Only a change of a part of the curriculum content and arrangement is not enough for deaf students.

We should educate them about the deaf culture. For instance, set up the school-based curriculum (a few deaf schools have the school-based curriculum, but the curriculum is short of scientificity. ${ }^{23}$ ) that describes the life experiences of successful deaf persons, describes the deeds of deaf heroes ${ }^{24}$, and organizes communication or cooperation among different deaf schools. Let deaf persons confide in themselves and gradually identify with the bicultural identity.

\subsection{Ameliorate the Public's Attitude to Deaf Culture}

The perspective that deaf people should be regarded primarily as a cultural and language minority group rather than as individuals with an audiological ${ }^{25}$ disability is gathering support among educators, linguists, and researchers involved in deaf education. ${ }^{26}$ The diversity should be accommodated and respected by the public, and we know this is the responsibility of the public.

Despite important stride made during the education and publicity, I have to say it is so difficult to shift thoroughly the attitude of the public, especially when it is a national attitude. I am not sure how to change the public's attitude.

Education and publicity of the viewing for the deaf culture may be the best way to enable the public to understand, accommodate and respect the deaf culture. How it will influence the attitude of the public thus remains an open question for a future study.

23 GAO LEI, LAN JIJUN, WANG JIANGNA, On the School-based Chinese-Language Teaching Material Development in Schools for the Deaf, Chinese Journal of Special Education, p. 33, Vol. 122(8), 2010

24 ZHANG NINGSHENG, WANG QI. A Study on Deaf Identity, Chinese Journal of Special Education, Vol. 109(7), p. 52, 2009.

25 At present, we prefer to use a more proper term: hearing impairment.

26 ILA PARASNIS, Cultural Identity and Diversity in Deaf Education, American Annals of the Deaf; Vol. 142(2), p. 72, Apr 1997; 142,2 


\section{References}

1. BENJAMIN R. FRASER, Deaf Cultural Production in Twentieth-Century Madrid, Sign Language Studies, Vol. 7(4), p. 431-457, summer 2007.

2. Cole, Susan H, Edelmann, Robert J, Identity Patterns and Self- and Teacher-perceptions of Problems for Deaf Adolescents: a Research Note, Journal of Child Psychology and Psychiatry and Allied Disciplines. Vol. 32(7), p. 1159-1165, Nov 1991.

3. Deborah L. Maxwell-McCaw, Irene W. Leigh, Alan L. Marcus Gallaudet University, Social Identity in Deaf Culture: A Comparison of Ideologies, used with permission, draft mailed to Journal of the American Deafness \& Rehabilitation Association.

4. GLICKMAN, NEIL S., CAREY, JOHN C. Measuring Deaf Cultural Identities: A Preliminary Investigation, Rehabilitation Psychology, Vol. 39(3), Fal, 1994.

5. GAO LEI, LAN JIJUN, WANG JIANGNA, On the School-based Chinese-Language Teaching Material Development in Schools for the Deaf, Chinese Journal of Special Education, p. 32-36, Vol. 122(8), 2010

6. HU YANMEI, Study on Deaf College Identity, Liaoning Normal University Ph.D. thesis, p. 41, 2005.

7. ILA PARASNIS, Cultural Identity and Diversity in Deaf Education, American Annals of the Deaf; Vol. 142(2), p. 72-79, Apr 1997.

8. JOANNA KOSSEWSKA, Personal Identity in Deaf Adolescents, Journal of Special Education and Rehabilitation, Vol. 1-2, p. 67-69, 2008

9. LIANGH HAO, Research on CSL Study by Hearing Teachers in Deaf School. Published on Internet, Jan, 2010.

10. MAGDA NIKOLARAIZI \& KIKA HADJIKAKOU, The Role of Educational Experiences in the Development of Deaf Identity, Journal of Deaf Studies and Deaf Education Vol. 11(4), Fall 2006.

11. RICHARD R. LYTLE, KATHRYN E. JOHNSON, YANG JUNHUI, Deaf Education in China: History, Current Issues, and Emerging Deaf Voices, American Annals of The Deaf, Vol. 150(5), 2005/2006.

12. TAN QIAOBAO, ZHONG YIPING, CHEN FANG, ZHOU SONGQING, Research on the Relationship Between Identity and Social Anxiety of Deaf Students, Chinese Journal of Clinical Psychology Vol. 18(4), p. 509-513, 2010. 
13. THOMAS K. HOLCOMB, Development of Deaf Bicultural Identity, American Annals of the Deaf, Vol. 142(2), Apr 1997.

14. YAEL BAT-CHAVA, Diversity of Deaf Identities, American Annals of the Deaf, Vol. 145(5), Dec 2000

15. ZHANG NINGSHENG, WANG QI. A Study on Deaf Identity, Chinese Journal of Special Education, Vol. 109 (7), p. 52, 2009.

\section{Contact}

Ge Chen,

doctoral student,

Institute of Special Education, Faculty of Education,

Palacký University, Olomouc, Czech Republic.

Faculty of Education Science, Sichuan Normal University

NO. 1819, Chenglong Avenue Longquanyi District

Chengdu city 610101, Sichuan province, P. R. China

e-mail: gechen80@163.com 